\title{
The differences in health-related quality of life between younger and older adults and its associated factors in patients with type 2 diabetes mellitus in Indonesia
}

\author{
Yunita Sari ${ }^{*}{ }^{*}$, Atyanti Isworo ${ }^{1}$, Arif Setyo Upoyo ${ }^{1}$, Agis Taufik' ${ }^{1}$, Rahmi Setiyani ${ }^{1}$, Keksi Girindra Swasti ${ }^{1}$,
} Haryanto Haryanto ${ }^{2}$, Saldy Yusuf ${ }^{3}$, Nasruddin Nasruddin ${ }^{4}$ and Ridlwan Kamaluddin ${ }^{1}$

\begin{abstract}
Background: It is well known that diabetes mellitus (DM) affects health-related quality of life (HRQOL) in both younger (aged 18-64 years) and older adults (aged $\geq 65$ years). However, to date, no study has compared HRQOL and its predictors between younger and older adults with DM in Indonesia. Such a comparison is important because the results can guide nurses and clinicians to establish evidence-based educational programs that are specific and suitable for patients. Therefore, the aim of this study was to investigate the difference in HRQOL and its predictors in younger and older adults with DM in Indonesia.
\end{abstract}

Methods: A cross-sectional study was conducted on 641 patients with type 2 diabetes mellitus (T2DM) who were recruited via simple random sampling from 16 primary health centers in Banyumas Regency, Indonesia. A self-administered questionnaire containing the Summary of Diabetes Self-Care Activities, the DDS17 Bahasa Indonesia, the Beck Depression Inventory II, the Self-Efficacy for Diabetes Scale, the Family APGAR, and the 36-item Short-Form Health Survey was used to measure diabetes self-management (DSM), diabetes distress (DD), depression, self-efficacy, family support, and HRQOL, respectively. Independent t-tests were used to compare the physical component summary (PCS) and mental component summary (MCS) scores between younger and older adults with T2DM. Hierarchical multiple regression analyses were used to examine the factors associated with HRQOL in both groups.

Results: PCS scores were significantly different between the two groups. Older adults reported lower PCS scores than younger adults. No differences between the two groups were observed in the MCS scores. The hierarchical multiple regression analysis showed that level of education, employment status, number of diabetes-related complications, DSM, DD, depression, and self-efficacy were significant predictors of HRQOL in younger adults, while income, depression, DD, and self-efficacy were significant predictors of $\mathrm{HRQOL}$ in older adults. DD was the strongest predictor of $\mathrm{HRQOL}$ in younger adults, and depression was the strongest predictor in older adults.

Conclusion: Older adult patients had lower PCS scores than younger adult patients. This study is the first to show that the predictors of HRQOL differ between younger and older adults with T2DM. It provides insights for nurses and clinicians in Indonesia to establish evidence-based, age-specific educational programs.

\footnotetext{
*Correspondence: sasa.yunita@gmail.com; yunita.sari@unsoed.ac.id

${ }^{1}$ Department of Nursing, Universitas Jenderal Soedirman, Purwokerto, Indonesia
}

Full list of author information is available at the end of the article permits use, sharing, adaptation, distribution and reproduction in any medium or format, as long as you give appropriate credit to the original author(s) and the source, provide a link to the Creative Commons licence, and indicate if changes were made. The images or other third party material in this article are included in the article's Creative Commons licence, unless indicated otherwise in a credit line to the material. If material is not included in the article's Creative Commons licence and your intended use is not permitted by statutory regulation or exceeds the permitted use, you will need to obtain permission directly from the copyright holder. To view a copy of this licence, visit http://creativecommons.org/licenses/by/4.0/. The Creative Commons Public Domain Dedication waiver (http://creativeco mmons.org/publicdomain/zero/1.0/) applies to the data made available in this article, unless otherwise stated in a credit line to the data. 
Keywords: Diabetes mellitus, Quality of life, Older younger adults, Predictor

\section{Background}

The number of patients with diabetes mellitus (DM) is increasing at an alarming rate. Global cases increased by 211 million between 2000 and 2013 [1, 2]. It is predicted that there will be 210 million new cases of DM between 2013 and 2035 [1]. It is commonly assumed that type 2 diabetes mellitus (T2DM) mainly affects older adults. However, data demonstrate that among the 382 million individuals with DM in 2013, the greatest number of patients were younger adults, and, of 5.1 million deaths due to DM, half were younger adults [3, 4].

The number of patients with DM is also increasing in Indonesia. Indonesia has the seventh largest number of patients with DM in the world [3], with nearly 11 million adults having been diagnosed with T2DM. The prevalence of DM in younger and older adults in Indonesia is similar, namely, $4.48 \%$ and $5.33 \%$, respectively [5]. Recently in Indonesia, the incidence of T2DM in younger adults has begun to rise [6,7].

DM has a significantly negative impact on healthrelated quality of life (HRQOL) in patients, either directly or because of its complications [8, 9]. Additionally, patients with DM tend to have poor HRQOL, especially in regard to physical and psychological functions [10]. Therefore, an assessment of the HRQOL of patients with DM is important because it can help to monitor treatment guidelines to avoid serious consequences. It will also identify individuals with poor HRQOL and predictors that could guide nurses and clinicians to establish evidence-based educational programs that are specific to and suitable for patients. A program based on predictors of HRQOL is important, especially in a developing country such as Indonesia, where resources are limited.

Among demographic variables, age is the most commonly reported predictor of HRQOL. In general, older adults have a worse HRQOL compared with younger adults [11]; however, this remains unclear in patients with DM. A study in patients with DM conducted between 2000 and 2020 found no difference in HRQOL between older and younger adults based on physical component summary (PCS) and mental component summary (MCS) scores [12]. However, this study was conducted in developed countries and, therefore, is not relevant to a developing country such as Indonesia. Additionally, no study has compared HRQOL between younger (aged $18-64$ years) and older adults (aged $\geq 65$ years) with DM in a developing country, for example, Indonesia. Therefore, difference in HRQOL between younger and older adults with DM is still unclear. Compared to those who live in developed countries, residents of developing countries usually have a lower economic status, a less healthy lifestyle, fewer resources, and lower quality of health care services [13]. These factors, taken alongside the consequences of aging and DM disease progression, allowed us to hypothesize that HRQOL in patients with DM in older adults would be lower than that of younger adults in Indonesia. Because no study has compared HRQOL between younger and older adults with DM in Indonesia, the main aim of this study was to investigate the differences in HRQOL between younger and older adults with DM in this country.

The variables that have been demonstrated to affect HRQOL in patients with DM are diabetes self-management (DSM), diabetes distress (DD), depression, selfefficacy, and family support [10, 14-17]. Although the predictors of HRQOL in patients with DM have been studied, it remains unclear whether they apply to both younger and older adult patients. If data on the differences in the predictors in both groups were available, it would be possible to establish evidence-based educational programs for improving HRQOL in patients with DM that were specific and suitable for each population. To effectively improve HRQOL, the predictors of HRQOL should be examined separately in younger and older adults. Therefore, the second aim of this study was to investigate the difference in the predictors of HRQOL between younger and older adults with DM.

\section{Methods}

\section{Research participants and data collection}

A cross-sectional study was conducted on patients with T2DM who were recruited via simple random sampling from 16 primary health centers in Banyumas Regency, Indonesia. The sample size was calculated using a $95 \%$ confidence level, prevalence of $13.4 \%$, and absolute precision of $3 \%$. Considering the response rate of $77.4 \%$ based on our previous study (unpublished), the total sample size calculated was 641 patients. The inclusion criteria were patients aged 18 or over who had been diagnosed with T2DM by their physician and were willing to sign the informed consent form. The exclusion criteria were patients with physical disabilities, cognitive or neurological impairments, or critical or advanced complications. The clinical data of patients were extracted from their medical records. The selection of a random samples was conducted by using a computer generated random sample (RAND function in Excel) to select 641 patients out of 1747 (total patients of 16 primary health centers). The 
ethical research committee at the Faculty of Health Sciences, Purwokerto, Indonesia, approved this study (059/ KEPK/II/2020 (11 February 2020).

\section{Demographic and clinical information}

Demographic and clinical variables related to HRQOL were assessed and studied. Variables were age, gender, marital status, level of education, employment status, income, body mass index (BMI), duration of DM, smoking status, number of diabetes-related complications, fasting blood glucose, presence of hypertension, and type of DM medication.

\section{Research instruments \\ Health-related quality of life}

HRQOL was measured using the 36-item Short-Form Health Survey (SF-36), one of the most widely used questionnaires for assessing HRQOL. Other studies have demonstrated that the SF-36 has high validity and reliability [18-20] and it has been validated in Indonesia. Cronbach's alpha of the Indonesian version of the SF-36 is satisfactory (higher than 0.7) [21]. The questionnaire is composed of eight domains (physical functioning, role limitations related to physical health problems, bodily pain, general health, vitality, social functioning, role limitations related to mental health, and mental health). These domains were scored from 0 to 100 and were clustered into PCS and MCS measures [22, 23], which were transformed into T-scores and normalized to the general population in the United States (mean $=50$, standard deviation $=10$ ) [20].

\section{Diabetes self-management}

DSM was assessed using a summary of the diabetes selfcare activities measure (SDSCA). This multidimensional instrument that assesses patient behavior in DSM was developed by Toobert et al. [24] and has been widely used in other countries [25-27]. The SDSCA is composed of a core set of 11 items and 14 extended items. The core items assess diet, exercise, blood-glucose testing, foot care, and smoking [24], while the extended items assess self-care recommendation, diet, medication, foot care, and smoking [24]. Possible responses range from 0 to 7 , according to the number of days patients performed selfcare over the past week. A higher score means better selfcare management. One study demonstrated the content validity of the SDSCA as being 0.83 and Cronbach's alpha as being 0.69 [27]. The Indonesian version of the SDSCA showed a Cronbach's alpha of 0.72 [28].

\section{Diabetes distress}

Diabetes-related emotional distress was assessed using DDS17 Bahasa Indonesia, which is an Indonesia version of the Diabetes Distress Scale questionnaire [29]. This scale contains four domains including interpersonal distress, emotional burden, physician-related distress, and regimen-related distress. There are 17 items on the scale, with each item being scored from 1 (not a problem) to 6 (a very serious problem). The total scores of the 17 items ranged from 17 (not a problem) to 102 (a very serious problem). This scale had a Cronbach's alpha between 0.78 and 0.83 [29].

\section{Depression}

The Beck Depression Inventory II (BDI II) is an instrument for assessing the severity of subjective depressive symptoms [30]. Composed of emotional, cognitive, motivational, and physiological items, the BDI II is one of the most widely used measures of depression. This scale has been validated in many countries, and had a Cronbach's alpha between 0.86 and 0.93 [31-33]. The Indonesian version of the BD II had a Cronbach's alpha between 0.74 and 0.81 [34]. The questionnaire is composed of 21 statements, with each statement being scored from 0 to 3 . The total score, up to a maximum of 63 , is obtained by adding each score for the 21 items. Higher scores indicate greater depression.

\section{Self-efficacy}

Self-efficacy was assessed using the self-efficacy for diabetes scale (SES) from the Stanford Patient Education Research Centre [35]. This questionnaire assesses how confident patients are in performing activities related to their diabetes, including diet management, exercise, blood glucose control, and illness management. The scale is composed of eight Likert-type scale items that range from 1 (not at all confident) to 10 (totally confident). This scale had a Cronbach's alpha of 0.82 [35] and the Indonesian version of SES showed similar Cronbach's alpha value (0.82) [36]. A score equal to or greater than the mean can be categorized as good self-efficacy [35].

\section{Family support}

Family support was assessed using the Family APGAR, which has been widely used to measure perceived family support in five domains: adaptation (A), partnership $(P)$, growth $(G)$, affection $(A)$, and resolve $(R)$ [37]. Other studies have demonstrated the tool's validity and reliability to be satisfactory $[37,38]$. A previous study showed that the Indonesian version of this questionnaire had a Cronbach's alpha of 0.83 [39]. Questions are ranked from 0 (hardly ever) to 2 (almost always). The highest possible overall score is 10, with a score of between 8 and 10 indicating a highly functional family, and a score below 8 indicating a dysfunctional family [40]. 


\section{Statistical analysis}

A statistical evaluation was conducted using SPSS version 22.0 (SPSS Inc., Chicago, IL, USA).

Descriptive statistics (mean, standard deviation, and percentage) were used to describe the demographic and clinical characteristics of the patients. Mean, and standard deviation were calculated for continuous data, and percentage values were calculated for discrete data. To identify whether the data were normally distributed, visual inspections of the histograms were performed and the Kolmogorov-Smirnov test was used. We found that the data were normally distributed. To identify differences between younger and older adults in the demographics and clinical characteristics, independent t-tests were used to compare interval variables and chi-square tests were used to compare categorical variables. Differences in HRQOL domains were analyzed using an independent t-test. Separate models were constructed to identify the predictors of HRQOL in younger and older adults. To identify the predictors of HRQOL in younger and older adults, a hierarchical multiple regression analysis was used. In the first block, DSM, DD, depression, self-efficacy, family support, and HRQOL were entered in the analysis. In the second block, demographic variables were jointly entered into the analysis. In the third block, the clinical data were jointly entered into the analysis. Tolerance and variance inflation factors were examined to detect multicollinearity. Tolerance values of less than 0.20 and variance inflation factor values higher than 5 indicated a multicollinearity problem [41-43].

\section{Results}

\section{Demographic characteristics}

The demographics and clinical characteristics of the patients are presented in Table 1. A total of 641 patients were included with a response rate of $100 \%$. Younger adult patients had a lower level of education $(p=0.032)$, lower income $(p=0.032)$, higher BMI $(p<0.001)$, shorter duration of DM $(p<0.01)$, fewer diabetes-related complications $(p=0.009)$, and higher fasting blood glucose levels than older patients $(p<0.01)$. There were no differences between the groups in employment status, smoking status, presence of hypertension, or type of DM medication used. These demographics and clinical characteristics were controlled in the subsequent analysis.

\section{HRQOL}

Controlling for demographic and clinical characteristics, the PCS score was significantly lower in older adults than in the younger adults (Table 2). The analysis of SF-36 sub-dimensions showed significant differences in physical function and role limitation due to physical problems: older adults, compared with younger adults, reported lower physical function $(p<0.001)$ and greater role limitation due to physical problems than younger adults $(p<0.001)$. After controlling for demographics and clinical characteristics, there was no significant difference in MCS scores between younger and older adults. The SF-36 sub-dimension analysis found that older adults had lower social function $(p<0.001)$ than younger adults.

\section{Predictors of HRQOL in younger adults}

The predictors of HRQOL in younger adults are shown in Table 3. In the first block, DSM, DD, depression, family support, and self-efficacy were entered into the analysis. The analysis showed that DSM, DD, depression, and self-efficacy were associated with HRQOL. Model 1 accounted for $26.4 \%$ of the variance observed in HRQOL. In the second block, the demographic variables were jointly entered into the analysis. DSM, DD, depression, and self-efficacy remained significant predictors for HRQOL. In the second block, the only demographic factor that became a significant predictor was the level of education. In the third block, clinical data were jointly entered into the analysis. DSM, DD, depression, self-efficacy, level of education, employment status, and number of diabetes-related complications were significant predictors of HRQOL $(\mathrm{F}=11.63, p<0.001)$. These variables accounted for $29.3 \%$ of the variance observed in HRQOL. The tolerance values of the third model ranged from 0.783 to $0.924(>0.20)$, and the variance inflation factor ranged from 1.023 to $1.373(\leq 5)$, indicating that the model did not exhibit multicollinearity problems. Therefore, a regression model was deemed appropriate.

\section{Predictors of HRQOL in older adult patients}

Predictors of HRQOL in older adults are shown in Table 4. In the first block, DD, depression, and self-efficacy were significant predictors of HRQOL. Model 1 accounted for $31.4 \%$ of the variance observed in HRQOL. In the second block, DD, depression, and self-efficacy remained significant predictors of HRQOL. Income was the only significant demographical factor in the second block. Model 2 accounted for $33.6 \%$ of the variance observed in HRQOL. In the third block, DD, depression, self-efficacy, and income were significant predictors of HRQOL. These variables accounted for $32.1 \%$ of the variance observed in HRQOL. The tolerance values of the third model ranged from 0.673 to $0.924(>0.20)$, and the variance inflation factor ranged from 1.083 to 1.486 $(\leq 5)$, indicating that the model did not exhibit multicollinearity. Therefore, a regression model was deemed appropriate. 
Table 1 Subject characteristics according to age

\begin{tabular}{|c|c|c|c|}
\hline \multirow[t]{4}{*}{ Characteristic } & Younger adults & Older adults & \multirow[t]{4}{*}{$p$ value } \\
\hline & $(18-64)$ years & $(\geq 65)$ years & \\
\hline & $(N=435)$ & $(N=206)$ & \\
\hline & Mean $( \pm S D)$ or $n(\%)$ & Mean $( \pm S D)$ or $n(\%)$ & \\
\hline Age & $55.32 \pm 6.80$ & $70.00 \pm 4.60$ & \\
\hline Gender & & & $0.008^{*}$ \\
\hline Male & $86(19.77)$ & $60(29.13)$ & \\
\hline Female & $349(80.23)$ & $146(70.87)$ & \\
\hline Marital status & & & $<0.001^{*}$ \\
\hline Single/never married & $8(1.84)$ & $2(0.97)$ & \\
\hline Married & $375(86.21)$ & $139(67.48)$ & \\
\hline Widowed & $52(11.95)$ & $65(31.55)$ & \\
\hline Level of education & & & $0.032^{*}$ \\
\hline |lliterate & $32(7.36)$ & $11(5.34)$ & \\
\hline Elementary school & $271(62.30)$ & $105(50.98)$ & \\
\hline Junior High School & $61(14.02)$ & $39(18.94)$ & \\
\hline Senior High School & $49(11.26)$ & $27(13.10)$ & \\
\hline College or higher & $22(5.06)$ & $24(11.65)$ & \\
\hline Employment status & & & 0.219 \\
\hline Employed & $186(42.76)$ & $92(44.66)$ & \\
\hline Unemployed & $249(57.24)$ & $114(55.34)$ & \\
\hline Income & & & $0.032^{*}$ \\
\hline Low income (less than USD 138 per month) & $389(89.43)$ & $171(83.00)$ & \\
\hline Middle income (USD 138-177 per month) & $36(8.28)$ & $31(15.06)$ & \\
\hline High income (higher than USD 177 per month) & $10(2.29)$ & $4(1.94)$ & \\
\hline$B M I$ & $24.32 \pm 4.70$ & $22.90 \pm 4.20$ & $<0.001^{*}$ \\
\hline Duration of DM & & & $<0.001^{*}$ \\
\hline Less than 1 year & $49(11.26)$ & $10(4.85)$ & \\
\hline $1-5$ years & $238(54.71)$ & $99(48.05)$ & \\
\hline $6-10$ years & $96(22.07)$ & $50(24.27)$ & \\
\hline More than 10 years & $52(11.96)$ & $47(22.81)$ & \\
\hline Smoking status & & & 0.295 \\
\hline Yes & $25(5.75)$ & $16(7.77)$ & \\
\hline No & $410(94.25)$ & $190(92.23)$ & \\
\hline Hypertension & & & 0.70 \\
\hline Yes & $278(63.91)$ & $143(69.42)$ & \\
\hline No & $157(36.09)$ & $63(30.58)$ & \\
\hline Number of diabetes related complications & & & $0.009^{*}$ \\
\hline No complications & 191(43.90) & $66(32.03)$ & \\
\hline One complication & $157(36.10)$ & $93(45.14)$ & \\
\hline Two or more complications & $87(20.0)$ & $47(22.81)$ & \\
\hline Fasting blood glucose (mg/dl) & $116 \pm 8.90$ & $104 \pm 42.70$ & $0.001^{*}$ \\
\hline Type of DM medication & & & 0.526 \\
\hline No medication & $26(5.98)$ & $17(8.25)$ & \\
\hline Insulin & $375(86.20)$ & $177(85.93)$ & \\
\hline Oral medication & $15(3.45)$ & $4(1.94)$ & \\
\hline Oral medication and insulin & $19(4.37)$ & $8(3.88)$ & \\
\hline
\end{tabular}

Data are expressed as group mean (SD) or percentage 
Table 2 Comparison of the PCS and MCS between younger and older adults

\begin{tabular}{|c|c|c|c|c|}
\hline \multirow[t]{2}{*}{ Variables } & $\begin{array}{l}\text { Younger adults (18-64) years } \\
(\mathrm{N}=435)\end{array}$ & $\begin{array}{l}\text { Older adults }(\geq 65) \text { years } \\
(N=206)\end{array}$ & $t$ & \multirow[t]{2}{*}{$p$ value } \\
\hline & Mean $( \pm S D)$ or $n(\%)$ & Mean $( \pm S D)$ or $n(\%)$ & & \\
\hline PCS & $49.90 \pm 5.52$ & $47.74 \pm 5.48$ & -4.626 & $<0.001^{*}$ \\
\hline Physical function & $83.90 \pm 16.30$ & $73.60 \pm 17.10$ & -7.348 & $<0.001^{*}$ \\
\hline Bodily pain & $56.30 \pm 24.80$ & $58.20 \pm 21.60$ & -1.114 & 0.266 \\
\hline General health & $65.50 \pm 10.00$ & $64.50 \pm 10.40$ & 0.984 & 0.325 \\
\hline Role limitation due to physical problems & $74.70 \pm 24.10$ & $68.90 \pm 23.50$ & -2.868 & $<0.001^{*}$ \\
\hline MCS & $38.16 \pm 3.25$ & $38.06 \pm 3.53$ & -0.320 & 0.749 \\
\hline Social function & $50.70 \pm 12.10$ & $44.40 \pm 12.60$ & -0.659 & $<0.001^{*}$ \\
\hline Vitality & $61.50 \pm 17.90$ & $60.60 \pm 16.40$ & 0.092 & 0.503 \\
\hline Mental health & $44.25 \pm 15.00$ & $43.90 \pm 14.10$ & -0.318 & 0.750 \\
\hline Role limitation due to emotional problems & $77.20 \pm 24.30$ & $75.10 \pm 25.50$ & -1.013 & 0.318 \\
\hline
\end{tabular}

Data are expressed as mean \pm standard deviation

$P C S$ physical component summary, MCS mental component summary ${ }^{*} p<0.05$

\section{Discussion}

This relatively large-scale cross-sectional study of patients with T2DM was the first study conducted in Indonesia to compare HRQOL between younger and older adults and its associated factors in patients with T2DM. The core finding of this study was that the predictors of HRQOL in younger adults were neither similar to nor different from those in older adults. We found seven predictors of HRQOL in younger adults, and four predictors of HRQOL in older adults. The predictors of HRQOL in younger adults were level of education, employment status, number of diabetes-related complications, DSM, DD, depression, and self-efficacy. The predictors of HRQOL in older adults were income, depression, DD, and self-efficacy. We also found DD to be a stronger predictor than depression in younger adults and depression to be a stronger predictor than DD in older adults. This is the first study to show that predictors of HRQOL in younger and older adults are not similar. This study provides new knowledge for the literature and evidence for nurses and clinicians to establish specific interventions to improve age-specific HRQOL for patients with T2DM in Indonesia.

In this study, older patients had a lower PCS scores than younger patients. Our findings differed from those of Trief et al. [12], who found the PCS level to be the same between both groups. The difference in PCS scores might be because in Indonesia, older adults tend to engage in lower levels of physical activity and have more diabetes complications than younger adults. Thus, we can see the importance of designing a program to improve PCS in older adults in Indonesia.
Somewhat surprisingly, our MCS results differed from our hypothesis. We found no difference between the MCS of younger and older adults. We also found that MCS scores in both younger and older adults were below those of the general population. This could be explained by the fact that all participants in our study tended to suffer from DD and depression. Most of the younger adults in this study had had DM for between one and five years. Thus, they might still be adapting to diabetes management. Another study showed that difficulty in following diabetes management could result in DD in adult patients [44]. In older adults, depression might result from the aging process and complications related to DM. Another possible reason is that most of the older adults in this study had a deceased spouse. Living alone is a risk factor for lower mental component-related HRQOL in older adults since no emotional support is given by a spouse [45-48]. According to Weiss's attachment theory, having a spouse can prevent individuals from suffering emotional loneliness that affects mental health [49]. Further research to explore the specific cause of DD and depression in both groups is necessary.

Our study found that both DD and depression were predictors of HRQOL, however, in younger adults, DD was a stronger predictor than depression, and in older adults, depression was a stronger predictor than DD. Many other studies have found that depression and DD affect HRQOL [50-52]. However, according to our review of the literature, this study was the first to show that when comparing DD and depression, DD was a stronger predictor for HRQOL in younger adults, and depression was a stronger predictor in older adults. DD 
Table 3 Predictors of $\mathrm{HRQOL}$ in younger adults patients with DM

\begin{tabular}{|c|c|c|c|}
\hline Variables & $\beta$ & $t$ & pvalue \\
\hline \multicolumn{4}{|l|}{ Steps 1} \\
\hline Constant & & 14.895 & $<0.001$ \\
\hline DSM & 0.155 & 3.537 & $<0.001^{*}$ \\
\hline DD & -0.295 & -6.236 & $<0.001^{*}$ \\
\hline Depression & -0.153 & -3.270 & $0.001^{*}$ \\
\hline Self-efficacy & 0.175 & 3.974 & $<0.001^{*}$ \\
\hline Family support & 0.035 & 0.831 & 0.407 \\
\hline \multicolumn{4}{|l|}{ Adjusted $R^{2}=0.264 ; F=32.38$ and $p<0.001$} \\
\hline \multicolumn{4}{|l|}{ Step 2} \\
\hline Constant & & 14.537 & $<0.001$ \\
\hline DSM & 0.146 & 3.327 & $0.001^{*}$ \\
\hline DD & -0.303 & -6.371 & $<0.001^{*}$ \\
\hline Depression & -0.144 & -3.102 & $0.002^{*}$ \\
\hline Self-efficacy & 0.162 & 3.675 & $<0.001^{*}$ \\
\hline Family support & 0.036 & 0.867 & 0.386 \\
\hline Gender & -0.009 & -0.200 & 0.842 \\
\hline Marital status & -0.040 & -0.957 & 0.339 \\
\hline Level of education & 0.119 & 2.737 & $0.006^{*}$ \\
\hline Employment status & 0.088 & 1.856 & 0.064 \\
\hline Income & 0.076 & 1.802 & 0.072 \\
\hline \multicolumn{4}{|l|}{ Adjusted $R^{2}=0.281 ; F=18.04$ and $p<0.001$} \\
\hline \multicolumn{4}{|l|}{ Step 3} \\
\hline Constant & & 9.981 & $<0.001$ \\
\hline DSM & 0.122 & 2.765 & $0.006^{*}$ \\
\hline DD & -0.288 & -5.827 & $<0.001^{*}$ \\
\hline Depression & -0.118 & -2.498 & $0.013^{*}$ \\
\hline Self-efficacy & 0.133 & 2.974 & $0.003^{*}$ \\
\hline Family support & 0.035 & 0.830 & 0.407 \\
\hline Gender & -0.011 & -0.234 & 0.815 \\
\hline Marital status & -0.033 & -0.805 & 0.421 \\
\hline Level of education & 0.097 & 2.228 & $0.026^{*}$ \\
\hline Employment status & 0.094 & 1.991 & $0.047^{*}$ \\
\hline Income & 0.081 & 1.910 & 0.057 \\
\hline $\mathrm{BMI}\left(\mathrm{kg} / \mathrm{m}^{2}\right)$ & 0.044 & 1.051 & 0.294 \\
\hline Duration of DM & -0.070 & -1.630 & 0.104 \\
\hline Smoking status & 0.067 & 1.555 & 0.121 \\
\hline $\begin{array}{l}\text { Number of diabetes-related complica- } \\
\text { tions }\end{array}$ & -0.106 & -2.364 & $0.019^{*}$ \\
\hline Fasting blood glucose & -0.051 & -1.252 & 0.211 \\
\hline Hypertension & 0.007 & 0.147 & 0.883 \\
\hline Type of DM medication & 0.047 & 1.127 & 0.260 \\
\hline Adjusted $R^{2}=0.293 ; F=11.64$, and $p$ & & & \\
\hline
\end{tabular}

In the first block, DSM, DD, depression, self-efficacy, and family support were entered into the analysis. In the second block, demographical factors were jointly entered into the analysis. In the third block, clinical data were jointly entered

$D S M$ diabetes self-management, $D D$ diabetes distress, $B M /$ body mass index ${ }^{*} p<0.05$
Table 4 Predictors of HRQOL in older adults patients with DM

\begin{tabular}{|c|c|c|c|}
\hline Variables & $\beta$ & $t$ & pvalue \\
\hline \multicolumn{4}{|l|}{ Steps 1} \\
\hline Constant & & 12.720 & $<0.001$ \\
\hline DSM & 0.030 & 0.487 & 0.627 \\
\hline DD & -0.204 & -3.197 & $0.002^{*}$ \\
\hline Depression & -0.346 & -5.314 & $<0.00^{*}$ \\
\hline Self-efficacy & 0.219 & 3.299 & $0.001^{*}$ \\
\hline Family support & 0.007 & 0.110 & 0.912 \\
\hline \multicolumn{4}{|c|}{ Adjusted $R^{2}=0.314 ; F=19.62$ and $p<0.001$} \\
\hline \multicolumn{4}{|l|}{ Step 2} \\
\hline Constant & & 11.440 & $<0.001$ \\
\hline DSM & 0.064 & 1.039 & 0.300 \\
\hline DD & -0.210 & -3.324 & $0.001^{*}$ \\
\hline Depression & -0.356 & -5.468 & $<0.001^{*}$ \\
\hline Self-efficacy & 0.211 & 3.215 & $0.002^{*}$ \\
\hline Family support & 0.005 & 0.081 & 0.935 \\
\hline Gender & -0.039 & -0.604 & 0.546 \\
\hline Marital status & -0.057 & -0.933 & 0.352 \\
\hline Level of education & 0.011 & 0.176 & 0.861 \\
\hline Employment status & 0.083 & 1.246 & 0.214 \\
\hline Income & 0.144 & 2.280 & 0.024 \\
\hline \multicolumn{4}{|l|}{ Adjusted $R^{2}=0.336 ; F=11.27$ and $p<0.001$} \\
\hline \multicolumn{4}{|l|}{ Step 3} \\
\hline Constant & & 7.707 & $<0.001$ \\
\hline DSM & 0.062 & 0.989 & 0.324 \\
\hline DD & -0.207 & -3.114 & $0.002^{*}$ \\
\hline Depression & -0.365 & -5.431 & $<0.001^{*}$ \\
\hline Self-efficacy & 0.202 & 2.998 & $0.003^{*}$ \\
\hline Family support & -0.006 & -0.098 & 0.922 \\
\hline Gender & -0.021 & -0.292 & 0.770 \\
\hline Marital status & -0.055 & -0.856 & 0.393 \\
\hline Level of education & 0.001 & 0.019 & 0.985 \\
\hline Employment status & 0.090 & 1.308 & 0.192 \\
\hline Income & 0.140 & 2.138 & $0.034^{*}$ \\
\hline BMI $\left(\mathrm{kg} / \mathrm{m}^{2}\right)$ & -0.050 & -0.816 & 0.416 \\
\hline Duration of DM & -0.005 & -0.090 & 0.928 \\
\hline Smoking status & -0.042 & -0.660 & 0.510 \\
\hline $\begin{array}{l}\text { Number of diabetes-related complica- } \\
\text { tions }\end{array}$ & 0.013 & 0.214 & 0.831 \\
\hline Fasting blood glucose & -0.043 & -0.715 & 0.475 \\
\hline Hypertension & -0.013 & -0.194 & 0.846 \\
\hline Type of DM medication & 0.053 & 0.840 & 0.402 \\
\hline Adjusted $R^{2}=0.321 ; F=6.64$ and $p<C$ & & & \\
\hline
\end{tabular}

In the first block, DSM, DD, depression, self-efficacy, and family support were entered into analysis. In the second block, demographical factors were jointly entered into analysis. In the third block, clinical data were jointly entered $D S M$ is diabetes self-management, $D D$ is diabetes distress, $B M I$ is body mass index 
refers to emotional distress related to living with and managing diabetes [53]. Many of the younger adults in this study had DM for less than five years, and many of the older adults had DM for more than five years. Therefore, we can assume that older adults knew how to manage the disease more effectively, as indicated by their ability to control their blood glucose better than the younger adults. The inability to manage DD might cause DD to become a stronger predictor in younger adults. Many younger adult patients in our study reported suffering mild depression, while many older adults reported moderate or severe depression. One study found that a depressive state has to be sufficient in intensity and duration to affect HRQOL [54]. This could be why, in younger adults, depression was not a stronger predictor than DD. The possible reasons for such differences require further research.

In this study, DSM was one of the predictors of HRQOL in younger adults but not in older adults. Our findings were not in accordance with those of Huang and Hung [55] who reported that DSM was also a predictor of HRQOL in older adults. A possible explanation for the difference is that older adults in Indonesia might perceive DSM to be a routine activity. Because of this they may perform diabetes self-care management only to maintain physical and emotional homeostasis, and therefore, it may not have significant effects on HRQOL.

Self-efficacy was found to be a predictor in both younger and older adults. DM patients with good selfefficacy means that they have confidence in their abilities to manage diabetes and influence disease outcomes [56]. Our study showed that individuals with higher levels of self-efficacy had better HRQOL. These results corresponded with those of Bowen et al. [16] who showed that self-efficacy was a predictor of HRQOL in patients with DM. Thus, a program to improve self-efficacy is necessary for both younger and older adults in Indonesia.

In this study, demographic variables that were found to be predictors of better HRQOL in younger adults were level of education, employment status, and number of diabetes-related complications. These results correspond with those of previous studies [57-60]. We also found that the main sociodemographic predictor of HRQOL in older adults was income. This finding supported those of two other studies that found older adults with a higher income to have a better HRQOL than those with a lower income [61, 62].

With this study, we identified predictors of HRQOL in younger and older T2DM patients in Indonesia. This study adds to the growing body of evidence that the predictors of HRQOL in younger and older patients are different. Based on our study findings, several actions should be taken. First, government and health clinicians should pay more attention to the physical and mental health of diabetic patients since this can affect HRQOL. Second, nurses and clinicians should create educational programs designed to improve DSM and patients' mental health in order to be able to manage DD and depression. Future studies are needed to evaluate the effectiveness of the implementation of educational programs in improving HRQOL.

This study had several limitations. First, since it was a cross-sectional study, no causal relationship could be drawn between the variables. Second, the study was conducted in Banyumas Regency and thus any extrapolation of the results to the rest of the Indonesian population should be carried out with caution. Third, we used the widely used QOL scale (SF-36] rather than a specific scale for HRQOL. Thus, there is a need for future research using a more specific scale. Finally, most patients in our study were female. While this could be perceived as a limitation, it does, however, represent the situation in Indonesia, since most DM patients in Indonesia are female.

Despite its limitations, our study also has strengths. First, it involved a large number of patients with DM in Indonesia. We had a high response rate and were able to form a representative sample regarding sociodemographics. Second, we used scales that have been validated in Indonesian settings. Third, this study was the first to examine the differences in HRQOL and its predictors in younger and older adults in T2DM patients in Indonesia. Therefore, the results of this study are critical for nurses and clinicians in Indonesia wanting to establish specific interventions to improve HRQOL in both groups. This study provides a foundation for further empirical studies on intervention methods to improve HRQOL based on the predictors we identified in both younger and older adults. There is a need for a larger, longitudinal study to assess the effects on HRQOL in patients who undergo specially designed programs.

\section{Conclusion}

This study is the first to compare HRQOL between younger and older adults and its associated factors in patients with T2DM in Indonesia. It provides evidence for nurses and clinicians in Indonesia to develop new approaches to improve HRQOL in both younger and older DM patients. The main findings of our study were the predictors of HRQOL in younger adults were neither similar to nor different from those in older adults. We found seven predictors of HRQOL in younger adults, and four predictors of HRQOL in older adults. The predictors of HRQOL in younger adults were level of education, employment status, number of diabetes-related complications, DSM, DD, depression, and self-efficacy, 
while the predictors of HRQOL in older adults were income, depression, DD, and self-efficacy. The strongest predictor of HRQOL in younger adults was DD, while the strongest predictor of HRQOL in older adults was depression. Nurses and clinicians should design educational programs for patients with DM to improve DSM, as well as to improve mental health to overcome DD and depression.

\section{Acknowledgements}

The author would like to thank the Ministry of Research and Technology/ National Research and Innovation Agency of Republic Indonesia for financially supporting this study.

\section{Authors' contributions}

YS performed the conceptualization and design of the study and drafted the manuscript. Al, AS, AT, RS, and KG conducted the data collection, interpreted data, and drafted the manuscript. HR, and SY conducted the interviews and statistical analyses. NS and RK performed the statistical analysis and drafted the manuscript. All authors read and approved the final manuscript.

\section{Funding}

This study was sponsored by the Ministry of Research and Technology/ National Research and Innovation Agency of the Republic of Indonesia under "World Class Research" scheme.

\section{Availability of data and materials}

The datasets of the current study are available from the corresponding author on request.

\section{Declarations}

\section{Ethical approval}

This study was approved by the Research Ethics Committee of the Faculty of Health Sciences, Universitas Jenderal Soedirman, Indonesia. Written informed consent was obtained from all participants before participating in this study.

\section{Competing interests}

The authors declare that they have no conflict of interest.

\section{Author details}

1 Department of Nursing, Universitas Jenderal Soedirman, Purwokerto, Indonesia. ${ }^{2}$ Department of Medical Surgical Nursing, STIK Muhammadiyah Pontianak, Pontianak, Indonesia. ${ }^{3}$ Faculty of Nursing, Hasanuddin University, Makassar, Indonesia. ${ }^{4}$ Department of Medical Laboratory Science, Faculty of Nursing and Health Sciences, Universitas Muhammadiyah Semarang, Semarang, Indonesia.

Received: 7 August 2020 Accepted: 25 March 2021

Published online: 16 April 2021

\section{References}

1. Forouhi NG, Wareham NJ. Epidemiology of diabetes. Medicine (Abingdon). 2014;42(12):698-702.

2. Wild S, Roglic G, Green A, Sicree R, King H. Global prevalence of diabetes: estimates for the year 2000 and projections for 2030. Diabetes Care. 2004;27(5):1047-53.

3. International Diabetes Federation. IDF Diabetes Atlas. 9th ed. Brussels: International Diabetes Federation; 2019.

4. IDF Diabetes Atlas Group. Update of mortality attributable to diabetes for the IDF Diabetes Atlas: estimates for the year 2013. Diabetes Res Clin Pract. 2015;109(3):461-5.

5. Sutanegara D, Budhiarta AAG. The epidemiology and management of diabetes mellitus in Indonesia. Diabetes Res Clin Pract. 2000;50:59-16.
6. Arifin B, van Asselt ADI, Setiawan D, Atthobari J, Postma MJ, Cao Q. Diabetes distress in Indonesian patients with type 2 diabetes: a comparison between primary and tertiary care. BMC Health Serv Res. 2019;19(1):773

7. PUSDATIN. Situasi dan analisis diabetes [Internet]. Jakarta. 2014 https://pusdatin.kemkes.go.id/download.php?file=download/pusda tin/infodatin/infodatin-diabetes.pdf.

8. Arifin B, Idrus LR, van Asselt ADI, Purba FD, Perwitasari DA, Atthobari J, et al. Health-related quality of life in Indonesian type 2 diabetes mellitus outpatients measured with the Bahasa version of EQ-5D. Qual Life Res. 2019;28(5):1179-90.

9. Trikkalinou A, Papazafiropoulou AK, Melidonis A. Type 2 diabetes and quality of life. World J Diabetes. 2017;8(4):120-9.

10. Zurita-Cruz JN, Manuel-Apolinar L, Arellano-Flores ML, Gutierrez-Gonzalez A, Najera-Ahumada AG, Cisneros-González N. Health and quality of life outcomes impairment of quality of life in type 2 diabetes mellitus: a cross-sectional study. Health Qual Life Outcomes. 2018;16(1):94.

11. Netuveli G, Wiggins RD, Hildon Z, Montgomery SM, Blane D. Quality of life at older ages: evidence from the English longitudinal study of aging (wave 1). J Epidemiol Community Health. 2006;60(4):357-63.

12. Trief PM, Wade MJ, Pine D, Weinstock RS. A comparison of healthrelated quality of life of elderly and younger insulin-treated adults with diabetes. Age Ageing. 2003;32(6):613-8.

13. Peters D, Garg A, Bloom G, Walker D, Brieger W, Rahman M. Poverty and access to health care in developing countries. Ann N Y Acad Sci. 2008;25(1136):161-71.

14. Al-Khaledi M, Al-Dousari H, Al-Dhufairi S, Al-Mousawi T, Al-Azemi R, Al-Azimi F, et al. Diabetes self-management: a key to better healthrelated quality of life in patients with diabetes. Med Princ Pract. 2018;27(4):323-31.

15. Chew BH, Mukhtar F, Sherina MS, Paimin F, Hassan NH, Jamaludin NK. The reliability and validity of the Malay version 17-item diabetes distress scale. Malays Fam Phys Off J Acad Fam Phys Malays. 2015;10(2):22-35

16. Bowen PG, Clay OJ, Lee LT, Vice J, Ovalle F, Crowe M. Associations of social support and self-efficacy with quality of life in older adults with diabetes. J Gerontol Nurs. 2015;41(12):21-31.

17. Meidikayanti W, Wahyuni CU. The correlation between family support with quality of life diabetes mellitus type 2 in Pademawu PHC. J Berk Epidemiol. 2017;5(2):240-52.

18. Tapp RJ, Dunstan DW, Phillips P, Tonkin A, Zimmet PZ, Shaw JE. Association between impaired glucose metabolism and quality of life: results from the Australian diabetes obesity and lifestyle study. Diabetes Res Clin Pract. 2006;74(2):154-61.

19. Ware JEJ, Sherbourne CD. The MOS 36-item short-form health survey (SF-36). I. Conceptual framework and item selection. Med Care. 1992;30(6):473-83.

20. Ware JE Jr. SF-36 health survey update. Spine (Phila Pa 1976). 2000;25(24):3130-9.

21. Salim S, Yamin M, Alwi I, Setiati S. Validity and reliability of the Indonesian version of SF-36 quality of life questionnaire on patients with permanent pacemakers. Acta Med Indones. 2017;49(1):10-6.

22. Pfoh ER, Chan KS, Dinglas VD, Cuthbertson BH, Elliott D, Porter $R$, et al. The SF-36 offers a strong measure of mental health symptoms in survivors of acute respiratory failure. A tri-national analysis. Ann Am Thorac Soc. 2016;13(8):1343-50

23. Iudici M, Cuomo G, Vettori S, Avellino M, Valentini G. Quality of life as measured by the short-form 36 (SF-36) questionnaire in patients with early systemic sclerosis and undifferentiated connective tissue disease. Health Qual Life Outcomes. 2013;25(11):23.

24. Toobert DJ, Hampson SE, Glasgow RE. The summary of diabetes self-care activities measure: results from 7 studies and a revised scale. Diabetes Care. 2000;23(7):943-50.

25. Kamradt M, Bozorgmehr K, Krisam J, Freund T, Kiel M, Qreini M, et al. Assessing self-management in patients with diabetes mellitus type 2 in Germany: validation of a German version of the summary of diabetes self-care activities measure (SDSCA-G). Health Qual Life Outcomes. 2014;12:185.

26. Gurmu Y, Gela D, Aga F. Factors associated with self-care practice among adult diabetes patients in West Shoa Zone, Oromia Regional State, Ethiopia. BMC Health Serv Res. 2018;18(1):732. 
27. Choi EJ, Nam M, Kim SH, Park CG, Toobert DJ, Yoo JS, et al. Psychometric properties of a Korean version of the summary of diabetes self-care activities measure. Int J Nurs Stud. 2011;48(3):333-7.

28. Sh S, Hsu YY, Toobert DJ, Wang ST. The validity and reliability of the summary of diabetes self-care activities questionnaire: an Indonesian version. Indones Nurs J Educ Clin. 2019;4(1):25.

29. Arifin B, Perwitasari DA, Atthobari J, Cao Q, Krabbe PFM, Postma MJ. Translation, revision, and validation of the diabetes distress scale for Indonesian type 2 diabetic outpatients with various types of complications. Value Heal Reg Issues. 2017;12:63-73.

30. Beck AT, Steer RA, Ball R, Ranieri WF. Comparison of beck depression inventories-IA and-II in psychiatric outpatients. J Pers Assess. 1996:67(3):588-97.

31. Gomes-Oliveira MH, Gorenstein C, Lotufo Neto F, Andrade LH, Wang YP. Validation of the Brazilian Portuguese version of the Beck depression inventory-II in a community sample. Rev Bras Psiquiatr. 2012;34(4):389-94.

32. Kojima M, Furukawa TA, Takahashi H, Kawai M, Nagaya T, Tokudome S. Cross-cultural validation of the Beck depression inventory-II in Japan. Psychiatry Res. 2002;110(3):291-9.

33. Segal DL, Coolidge FL, Cahill BS, O'Riley AA. Psychometric properties of the Beck depression inventory II (BDI-II) among community-dwelling older adults. Behav Modif. 2008;32(1):3-20.

34. Ginting H, Näring $G$, van der Veld WM, Srisayekti W, Becker ES. Validating the Beck depression inventory-II in Indonesia's general population and coronary heart disease patients. Int J Clin Heal Psychol. 2013;13(3):235-42.

35. Stanford Patient Education Research Center. Self-Efficacy for Diabetes. 2019. https://www.selfmanagementresource.com/docs/pdfs/English_self-efficacy_diabetes.pdf.

36. Silolonga WN. Adaptasi dan pengembengan instrumen diabetes selfefficacy (DSES) versi indonesia untuk penderita diabetes mellitus tipe 2. Master Thesis. Hasanuddin University; 2018.

37. Smilkstein G. The family APGAR: a proposal for a family function test and its use by physicians. J Fam Pract. 1978;6(6):1231-9.

38. da Silva MJ, Victor JF, Mota FRDN, Soares ES, Leite BMB, Oliveira ET. Analysis of psychometric properties of family APGAR with elderly in northeast Brazil. Esc Anna Nery. 2014;18(3):527-32.

39. Mutmainah A, Kusnanto H, Hilman O. The effect of family APGAR score on depression rate in type 2 diabetes mellitus patients at first-level health facilities. Rev Prim Care Pract Educ. 2018;1(2):62.

40. Takenaka $\mathrm{H}, \mathrm{Ban} \mathrm{N}$. The most important question in family approach: the potential of the resolve item of the family APGAR in family medicine. Asia Pac Fam Med. 2016;5(15):3.

41. González-Blanch C, Hernández-de-Hita F, Muñoz-Navarro R, Ruíz-Rodríguez $\mathrm{P}$, Medrano LA, Cano-Vindel A. The association between different domains of quality of life and symptoms in primary care patients with emotional disorders. Sci Rep. 2018;8(1):11180.

42. Alves Costa MS, Pereira MG. Predictors and moderators of quality of life in caregivers of amputee patients by type 2 diabetes. Scand J Caring Sci. 2018;32(2):933-42.

43. Field A. Discovering statistics using SPSS ISM (London, England) introducing statistical methods series. London: SAGE Publications; 2009.

44. Nanayakkara N, Pease A, Ranasinha S, Wischer N, Andrikopoulos S, Speight J, et al. Depression and diabetes distress in adults with type 2 diabetes: results from the Australian National Diabetes Audit (ANDA) 2016. Sci Rep. 2018;8(1):7846.

45. de Belvis AG, Avolio M, Spagnolo A, Damiani G, Sicuro L, Cicchetti A, et al. Factors associated with health-related quality of life: the role of social relationships among the elderly in an Italian region. Public Health. 2008:122(8):784-93.
46. Gee EM. Living arrangements and quality of life among Chinese Canadian elders. Soc Indic Res. 2000;51(3):309-29.

47. Chou K-L, Chi I. Comparison between elderly Chinese living alone and those living with others. J Gerontol Soc Work. 2000;33(4):51-66.

48. I wasa H, Kawaai C, Gondo Y, Inagaki H, Suzuki T. Subjective well-being as a predictor of all-cause mortality among middle-aged and elderly people living in an urban Japanese community: a seven-year prospective cohort study. Geriatr Gerontol Int. 2006;6(4):216-22.

49. Weiss RS. Loneliness: The experience of emotional and social isolation. Cambridge: The MIT Press; 1973. p. xxii, 236-xxii, 236.

50. Mut-Vitcu G, Timar B, Timar R, Oancea C, Citu IC. Depression influences the quality of diabetes-related self-management activities in elderly patients with type 2 diabetes: a cross-sectional study. Clin Interv Aging. 2016;11:471-9.

51. Wang RH, Wu LC, Hsu HY. A path model of health-related quality of life in Type 2 diabetic patients: a cross-sectional study in Taiwan. J Adv Nurs. 2011;67(12):2658-67.

52. Jannoo Z, Wah YB, Lazim AM, Hassali MA. Examining diabetes distress, medication adherence, diabetes self-care activities, diabetes-specific quality of life and health-related quality of life among type 2 diabetes mellitus patients. J Clin Transl Endocrinol. 2017;9:48-54.

53. Arifin B, Probandari A, Purba AKR, Perwitasari DA, Schuiling-Veninga CCM, Atthobari J, et al. "Diabetes is a gift from god" a qualitative study coping with diabetes distress by Indonesian outpatients. Qual Life Res. 2020;29(1):109-25.

54. Fisher L, Mullan JT, Arean P, Glasgow RE, Hessler D, Masharani U. Diabetes distress but not clinical depression or depressive symptoms is associated with glycemic control in both cross-sectional and longitudinal analyses. Diabetes Care. 2010;33(1):23-8.

55. Huang M-C, Hung C-H. Quality of life and its predictors for middleaged and elderly patients with type 2 diabetes mellitus. J Nurs Res. 2007;15(3):193-201.

56. Song $\mathrm{R}, \mathrm{Ahn} \mathrm{S}, \mathrm{Oh} \mathrm{H}$. A structural equation model of quality of life in adults with type 2 diabetes in Korea. Appl Nurs Res. 2013;26(3):116-20.

57. Flatz A, Casillas A, Stringhini S, Zuercher E, Burnand B, PeytremannBridevaux I. Association between education and quality of diabetes care in Switzerland. Int J Gen Med. 2015;25(8):87-92.

58. Didarloo A, Alizadeh M. Health-related quality of life and its determinants among women with diabetes mellitus: a cross-sectional analysis. Nurs Midwifery Stud. 2016:5(1):e28937-e28937.

59. Abedini MR, Bijari B, Miri Z, Shakhs Emampour F, Abbasi A. The quality of life of the patients with diabetes type 2 using EQ-5D-5 L in Birjand. Health Qual Life Outcomes. 2020;18(1):18.

60. Rwegerera GM, Moshomo T, Gaenamong M, Oyewo TA, Gollakota S, Rivera YP, et al. Health-related quality of life and associated factors among patients with diabetes mellitus in Botswana. Alex andria J Med. 2018:54(2):111-8.

61. Alshayban D, Joseph R. Health-related quality of life among patients with type 2 diabetes mellitus in Eastern Province, Saudi Arabia: a crosssectional study. PLOS ONE. 2020;15(1):e0227573.

62. Prazeres F, Figueiredo D. Measuring quality of life of old type 2 diabetic patients in primary care in Portugal: a cross-sectional study. J Diabetes Metab Disord. 2014:13:68.

\section{Publisher's Note}

Springer Nature remains neutral with regard to jurisdictional claims in published maps and institutional affiliations. 